\title{
Approval for Database Activation Document
}

National Cancer Institute

\section{Source}

National Cancer Institute. Approval for Database Activation Document. NCI Thesaurus. Code C115634.

Records of the completion of all requirements for a database activation specification. 